\title{
A Modified Empirical Retracker for Lake Level Estimation Using Cryosat-2 SARin Data
}

\author{
Hui Xue ${ }^{1,2}$, Jingjuan Liao ${ }^{1, *}$ and Lifei Zhao ${ }^{3}$ \\ 1 Key Laboratory of Digital Earth Science, Institute of Remote Sensing and Digital Earth, \\ Chinese Academy of Sciences, Beijing 100094, China; xuehui@radi.ac.cn \\ 2 University of Chinese Academy of Sciences, Beijing 100049, China \\ 3 Hebei Sales Branch of PetroChina Company Limited, Shijiazhuang 050000, China; hmwhatdoi@hotmail.com \\ * Correspondence: liaojj@radi.ac.cn; Tel.: +86-010-8217-8160
}

Received: 29 September 2018; Accepted: 2 November 2018; Published: 5 November 2018

check for updates

\begin{abstract}
Satellite radar altimetry is an important technology for monitoring water levels, but issues related to waveform contamination restrict its use for rivers, narrow reservoirs, and small lakes. In this study, a novel and improved empirical retracker (ImpMWaPP) is presented that can derive stable inland lake levels from Cryosat-2 synthetic aperture radar interferometer (SARin) waveforms. The retracker can extract a robust reference level for each track to handle multi-peak waveforms. To validate the lake levels derived by ImpMWaPP, the in situ gauge data of seven lakes in the Tibetan Plateau are used. Additionally, five existing retrackers are compared to evaluate the performance of the proposed ImpMWaPP retracker. The results reveal that ImpMWaPP can efficiently process the multi-peak waveforms of the Cryosat-2 SARin mode. The root-mean-squared errors (RMSEs) obtained by ImpMWaPP for Qinghai Lake, Nam Co, Zhari Namco, Ngoring Lake, Longyangxia Reservoir, Bamco, and Dawa Co are 0.085 m, 0.093 m, 0.109 m, 0.159 m, 0.573 m, 0.087 m, and 0.122 m, respectively. ImpMWaPP obtains the lowest mean RMSE $(0.175 \mathrm{~m})$ over the seven lakes, indicating that it extracts lake levels well during icing and no-ice periods, and is more suitable for lakes frozen in winter.
\end{abstract}

Keywords: Cryosat-2 SARin; multi-peak waveform; modified retracker; lake level

\section{Introduction}

Satellite radar altimetry has been used successfully for more than two decades to measure water levels over inland waters [1-7]. Unfortunately, its use for rivers, narrow reservoirs, and small lakes has been restricted by waveform contamination caused by it's relatively large footprint [8,9]. For conventional pulse-limited altimeters such as the TOPEX/Poseidon family of satellites, the footprint diameter is typically 5-10 km in mountainous areas [10], making it difficult to monitor small lakes. Cryosat-2 ushered in a new era in radar altimetry. It was launched by the European Space Agency (ESA) in April 2010 and is still operating. Because of its high along-track resolution and dense spatial sampling, the Cryosat-2 satellite is an important data source for monitoring lake levels, especially those of small lakes [11-15]. However, the footprint of Cryosat- 2 in the cross-track direction is still sufficiently large to cause some waveforms to be polluted by signals from nearby terrain.

Cryosat-2 carries on board a state-of-the-art synthetic aperture interferometric radar altimeter (SIRAL) that has three measurement modes, namely low resolution (LR), synthetic aperture radar (SAR), and SAR interferometer (SARin). These modes cover different regions, with the SARin mode being mainly activated over mountainous regions such as the Tibetan Plateau and the Andes [13]. The SARin mode includes an additional receiving antenna that allows the position of the reflecting surface to be determined [15], and it has a $300 \mathrm{~m}$ along-track resolution, but its footprint ranges up to 
$15 \mathrm{~km}$ in the cross-track direction. Thus, the SARin waveforms can be contaminated by land signals by an amount that is closely related to lake shape and surrounding terrain. Additionally, the SARin waveform features a steep leading edge and a faster-decaying trailing edge [16] that allow polluted waveforms to contain multiple distinguishable surface heights [10]. Therefore, retracking the SARin waveforms is a challenging task [10].

Previous studies have paid little attention to retracking algorithms for the Cryosat-2 SARin waveforms, particularly the applications to lakes. Kleinherenbrink et al. proposed a retracking algorithm based on cross-correlation of simulated and observed Cryosat-2 SARin waveforms [10]. Villadsen et al. and Nielsen et al. explored the performance of various retrackers for Cryosat-2 SAR waveforms $[17,18]$. Göttl et al. focused on processing the Cryosat-2 SAR waveforms by waveform classification and an improved threshold retracker (ITR) [19]. Gommenginger et al. systematically described those retrackers that could handle different types of LR mode waveform [20]. Typically, the retrackers in those studies did not account fully for the complexity of terrain and interferometry in Cryosat-2 SARin observations, making them weak at handling complex multi-peak waveforms. Furthermore, some previous studies discarded complex data, an approach that could lead to significant data loss, especially for small lakes [21]. The present paper considers various shapes of along-track waveform and presents an improved algorithm that integrates the advantages of the error mixture model and the Multiple Waveform Persistent Peak (MWaPP) retracker [17,18]. This algorithm uses a novel method for identifying the water's leading edge, thereby improving the processing performance for multi-peak waveforms. Furthermore, the capabilities of five existing algorithms for handling Cryosat-2 SARin waveforms are explored. In previous studies, examination of these retrackers was focused mainly on the Cryosat-2 SAR waveforms of low-elevation lakes, with mountainous lakes ignored. Compared with the waveforms of lakes surrounded by low topography, those of lakes with complex surrounding terrain are more susceptible to being polluted by land signals [7], especially near the shore.

The present study focuses on developing an improved retracker for processing Cryosat-2 SARin waveforms to obtain high-precision water levels. The water levels for seven Tibetan Plateau lakes derived from the new retracker and five existing retrackers are compared with in situ gauge data.

\section{Study Areas and Data}

\subsection{Study Areas}

Seven lakes in the Tibetan Plateau were chosen as study areas, each having in situ water levels and varying characteristics (e.g., extent, morphology, and surrounding landscape) (Figure 1). Their names are Qinghai Lake, Nam Co, Zhari Namco, Ngoring Lake, Longyangxia Reservoir, Bamco, and Dawa Co. They have the following characteristics: (1) The topography surrounding these lakes features large fluctuations, with the maximum change being up to several hundred meters. (2) The average altitude is more than $2500 \mathrm{~m}$ and ice formations are present in winter. The freezing time is generally from November of that year to April of the following year. (3) Longyangxia Reservoir is an artificial lake whose water levels are controlled by a management agency, but the other lakes have been rarely affected by human activities. The details of all the lakes are given in Table 1. It should be noted that Longyangxia Reservoir and Qinghai Lake were observed by the Cryosat-2 SARin mode only after December 2015.

\subsection{Data}

\subsubsection{Water Mask: The 2014 Sub-Dataset}

Water masks were used to extract the observations over all the lakes and were gathered from the 2014 sub-dataset for Tibetan Plateau lakes [22]. The latest status of each of 1171 lakes with an area greater than $1 \mathrm{~km}^{2}$ in the Tibetan Plateau is given in this dataset, including name, location, morphology, 
and area. This dataset was obtained by interpreting 11 Landsat- 8 Operational Land Imager (OLI) images acquired in 2014 and 136 Chinese Gaofen-1 images with wide-field-of-view cameras.
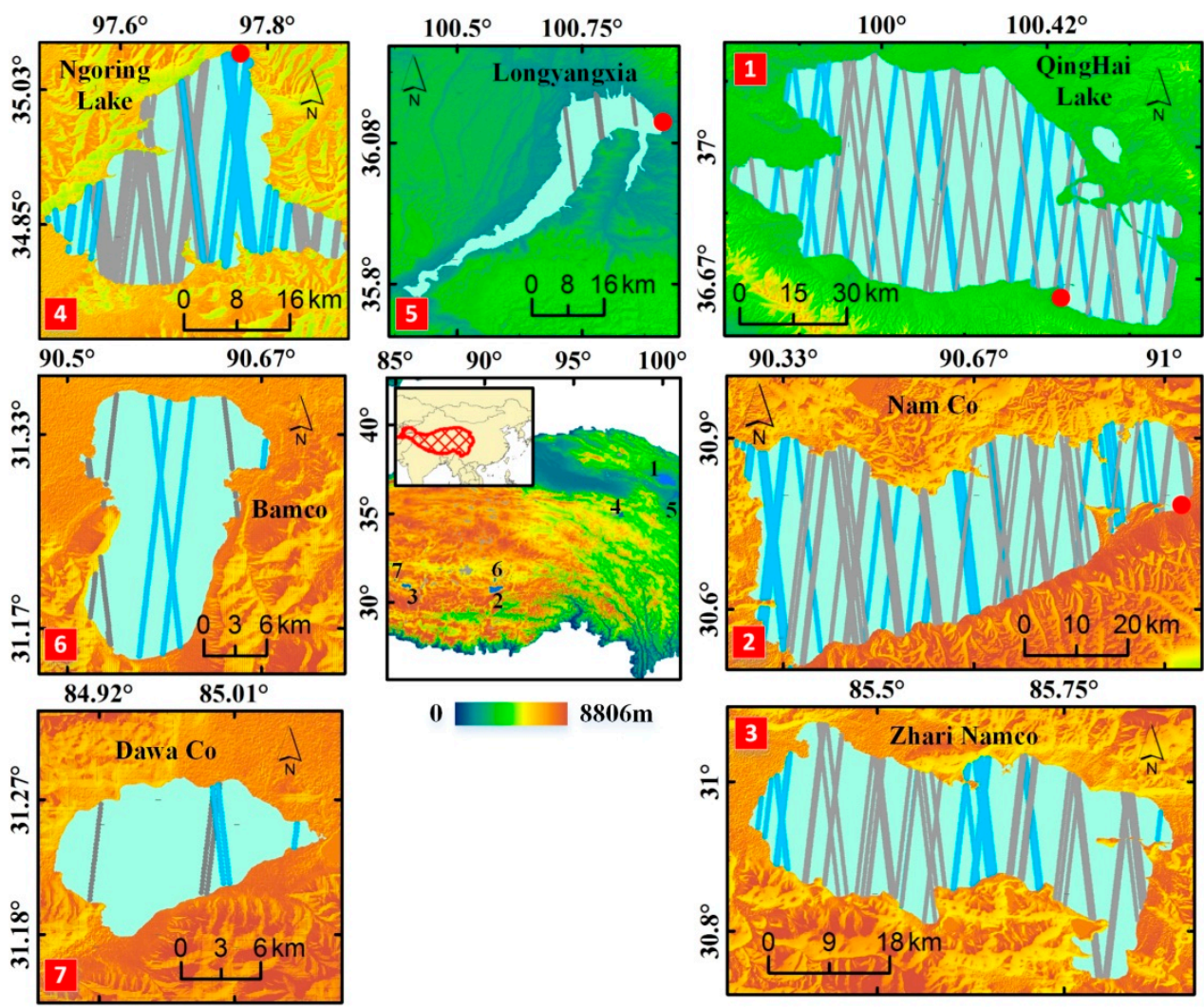

Figure 1. Lakes and corresponding Cryosat-2 SARin tracks. Blue and gray solid lines represent the observations of icing and no-ice periods, respectively. Red circles mark the locations of fixed measuring stations.

Table 1. Details of the seven lakes used in the present study.

\begin{tabular}{ccccccc}
\hline Lake Name & Coordinates & Area $\left[\mathbf{k m}^{\mathbf{2}}\right]$ & Altitude $^{\mathbf{1}}[\mathbf{m}]$ & Tracks $^{\mathbf{2}}$ & Date & Mode \\
\hline Qinghai Lake & $100.20,36.89$ & 4435 & 3194 & 49 & $01 / 2016-08 / 2017$ & Absolute \\
Nam Co & $90.60,30.74$ & 1920 & 4724 & 79 & $11 / 2010-12 / 2014$ & Relative \\
Zhari Namco & $85.61,30.93$ & 1023 & 4612 & 59 & $04 / 2010-12 / 2014$ & Relative \\
Ngoring Lake & $97.70,34.90$ & 610 & 4267 & 58 & $09 / 2010-12 / 2015$ & Absolute \\
Longyangxia & $100.73,36.01$ & 359 & 2569 & 5 & $12 / 2015-06 / 2017$ & Absolute \\
Bamco & $90.58,31.27$ & 180 & 4560 & 8 & $06 / 2013-12 / 2014$ & Relative \\
Dawa Co & $84.96,31.24$ & 118 & 4623 & 6 & $06 / 2013-12 / 2014$ & Relative \\
\hline
\end{tabular}

${ }^{1}$ Altitudes are from the Shuttle Radar Topography Mission (SRTM) Digital Elevation Model (DEM); ${ }^{2}$ Tracks column shows number of tracks for each lake.

\subsubsection{Cryosat-2 SARin Data}

SIRAL carried by Cryosat- 2 is the world's first space-borne altimeter featuring delayed Doppler technology [16]. The Cryosat-2 SARin Baseline $C$ version of Level- $1 b$ and Level-2 data products were used in the present study (ftp:/ / science-pds.cryosat.esa.int). Each 20-Hz waveform given by the Level-1b data consists of 1024 bins (Figure 2) and includes some improvements compared to the Baseline $B$ data product [23]. All observations were selected by the nadir positions given by the Level- $1 \mathrm{~b}$ data. Figure 2a,b shows typical Cryosat-2 SARin waveforms from water and ice surfaces, respectively. 

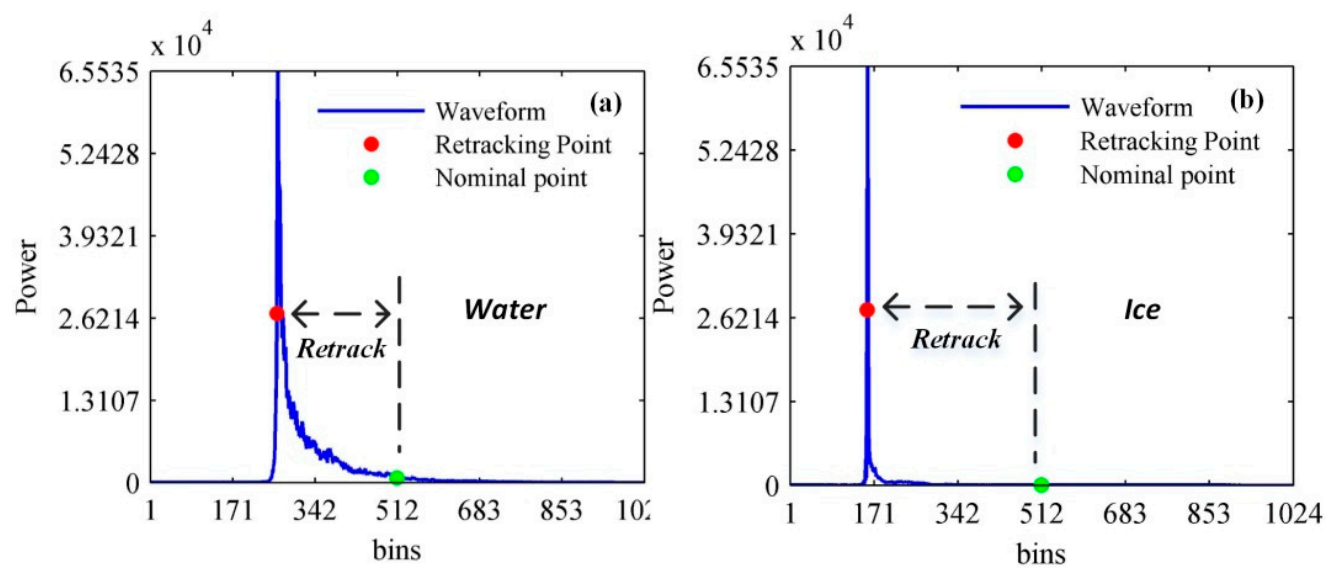

Figure 2. (a) Water surface waveform and (b) ice surface waveform. Green and red points mark the nominal tracking and retracking points, respectively.

In addition, the Level-2 data provides the retracked heights based on the Wingham-Wallis fitting algorithm (ESAL2) [13]. Because of interferometric processing, the observation position (Level-2 position) in the Level-2 data has been relocated, and the Level-2 data contains many off-nadir observations with high noise [10]. A track over Ngoring Lake and the corresponding waveforms is shown in Figure 3 and Appendix A. There are clearly many off-nadir observations from $34.82^{\circ}$ to $34.85^{\circ}$, such as spots 6 and 9 , and their waveforms are very complex. These waveforms with high noise may affect the stability of the statistical method in Section 3.3.
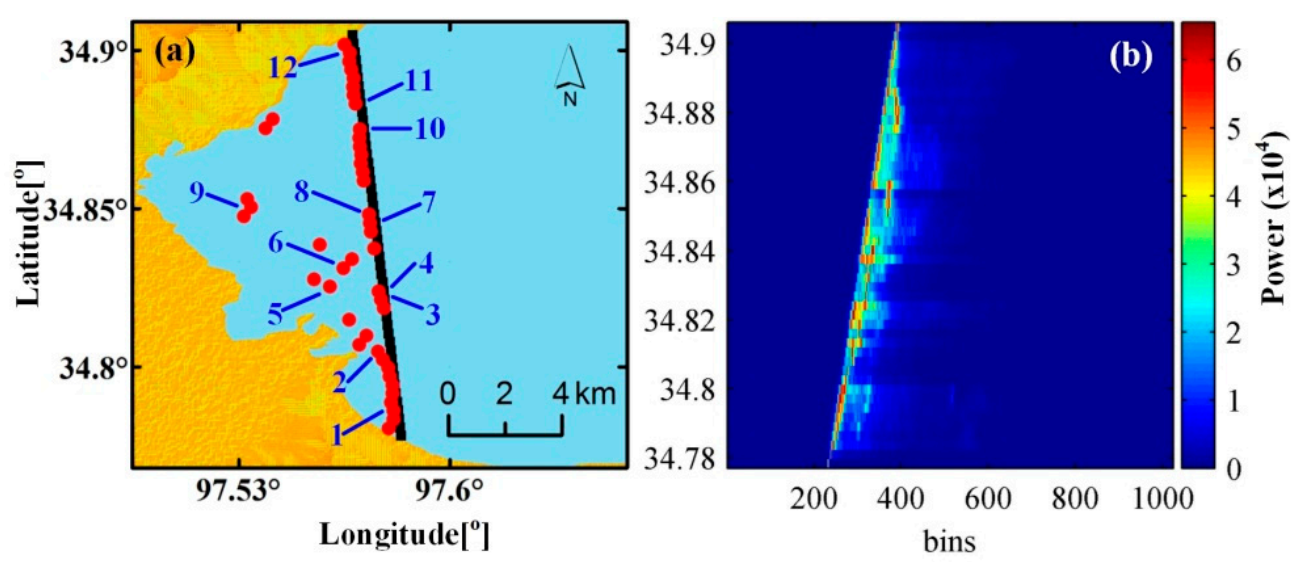

Figure 3. (a) Track over Ngoring Lake on 5 June 2011 (black and red solid points represent nadir and corresponding Level-2 positions of all observations, respectively), and (b) corresponding waveforms.

\subsubsection{In Situ Data}

The in situ data for three lakes (Qinghai Lake, Ngoring Lake, and Longyangxia Reservoir) is from (i) the Hydrology and Water Resources Survey Bureau in Qinghai Province, (ii) China's hydrological yearbooks, and (iii) the Yellow River Commission of the Ministry of Water Resources (http://www.yellowriver.gov.cn/), respectively. The data is referenced to China's 1985 National Height Datum.

The in situ data for Nam Co, Zhari Namco, Bamco, and Dawa Co is from the Institute of Tibetan Plateau Research, Chinese Academy of Sciences. Table 1 lists the measurement time and mode of the in situ data of the seven lakes. All in situ water levels are daily measurements, and the relative in situ data is measured by manually placed water-level gauges. 


\section{Methods}

\subsection{Estimation of Lake Level}

The water level $H$ with respect to the 2008 Earth Gravitational Model (EGM2008) [24] geoid was obtained using

$$
H=H_{\text {alt }}-H_{\text {range }}-N_{\text {geoid }}
$$

where $H_{\text {alt }}$ is the satellite altitude and $N_{\text {geoid }}$ is the geoid height with respect to the ellipsoid. $H_{\text {range }}$ is the range and is computed as

$$
H_{\text {range }}=\frac{c}{2} W D+R_{\text {retrack }}+H_{\text {geo }}
$$

where $c$ is the speed of light, $W D$ is the window delay in seconds relative to the central range bin, $R_{\text {retrack }}$ is the retracking correction (Figure 2), and $H_{\text {geo }}$ is the geophysical corrections, including ionosphere, dry troposphere, wet troposphere, solid earth tide, pole tide, and ocean loading tide. Both WD and $H_{\text {geo }}$ are included in the Level-1b data product.

In addition, to validate the water levels derived from the different algorithms, several extra processing steps were required. (1) The track mean level was calculated using the static error mixture model described in Reference [18], and the track standard deviation of the lake level was obtained after removing the outliers using one standard deviation from the track mean level. (2) After removing the abnormal track mean levels by visual inspection, the Cryosat-2 time series was obtained using Gaussian filtering on the remaining track mean levels [25,26]. (3) For each Cryosat-2 time series, a constant offset with respect to the in situ data was computed and removed, so has the same mean value as the in situ data [19].

\subsection{Improved Multiple Waveform Persistent Peak Retracker (ImpMWaPP)}

In this section the new ImpMWaPP retracker is presented, which is a modified algorithm based on the MWaPP retracker given by Reference [17]. For this retracker, a reliable reference water level per track was obtained and used to identify the part of the waveform (subwaveform) reflected by the water directly beneath the satellite. The steps of the new retracker are illustrated in Figure 4.

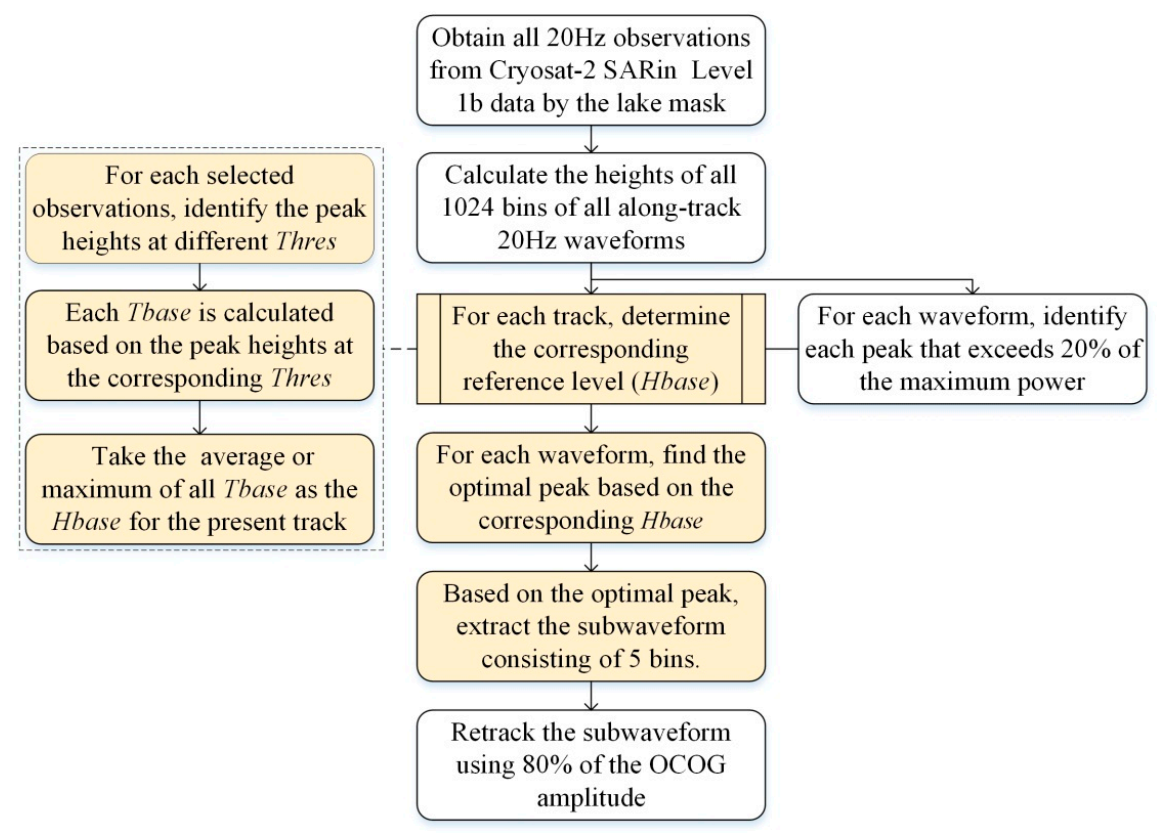

Figure 4. Flowchart describing the Improved Multiple Waveform Persistent Peak Retracker (ImpMWaPP). Steps with yellow background are different from the MWaPP retracker. 
First, for each Cryosat-2 SARin 20-Hz waveform, the heights corresponding to all bins were determined according to Equation (3). Thus, a bin height $H_{b i n}(i, j)$ was estimated for each $i=1, \ldots, p$ and $j=1, \ldots, k$, where $p$ is the number of the waveforms in the track and $k$ is the number of the bins in each waveform.

$$
H_{b i n}(i, j)=H_{\text {alt }}(i)-\frac{c}{2} W D+w_{b}\left(k_{o}-j\right)-H_{\text {geo }}(i)-N_{\text {geoid }}(i),
$$

where $H_{\text {alt }}$ is the satellite altitude, $c$ is the speed of light, $W D$ is the window delay, $w_{b}$ is the bin width ( $0.2342 \mathrm{~m}$ for Cryosat-2 SARin mode waveforms), $k_{0}$ is the nominal range bin number ( 512 for Cryosat-2 SARin), $H_{g e o}$ is the sum of the applied geophysical corrections, and $N_{\text {geoid }}$ is the geoid correction.

Second, the reference water level $H_{\text {base }}$ for each track was determined. The details are described in Section 3.3. Generally, because the height from a water surface is more stable than that from land, Hbase is determined by a robust statistical method. Compared to MWaPP, ImpMWaPP uses Hbase instead of the average waveform to identify the leading edge of water reflection, an approach that is better at avoiding noise effects.

Third, for each Cryosat-2 SARin 20-Hz waveform, the peak where power exceeded $20 \%$ of the maximum power and the corresponding bin height was closest to Hbase was found. Thus, a subwaveform comprising the bin of the peak and its two previous and two subsequent bins was extracted.

Finally, the off-center-of-gravity (OCOG) amplitude $A$ [27] for each extracted subwaveform was calculated by

$$
A=\sqrt{\frac{\sum_{L=1}^{N_{p p}} P_{L}^{4}(t)}{\sum_{L=1}^{N_{p p}} P_{L}^{2}(t)}}
$$

where $N_{p p}$ is the number of bins in the subwaveform and $P_{L}(t)$ is the power for each $L=1, \ldots, N_{p p}$. The point at which the subwaveform exceeds $80 \%$ of $A$ was marked as the retracking point.

\subsection{Determination of Reference Water Level Hbase}

First, the observations used to calculate Hbase were selected. To reduce the effects of noise, the off-nadir observations were removed by a distance threshold $D$. For each observation in the track, if the distance between its nadir and corresponding Level-2 position was larger than $D$, then it was removed. Each track has a unique $D$, which can be determined by the following steps.

(1) Calculate the distance between the nadir and corresponding Level-2 position for each observation in the present track, and construct the cumulative distribution function (CDF) of these distances at $100 \mathrm{~m}$ intervals. After this, we can obtain the distance corresponding to the minimum second-order difference quotient of this CDF, which is considered as D1.

(2) Repeat step 1 for all observations of all tracks over the lake and obtain another distance as D2.

(3) The minimum of $D 1$ and $D 2$ is finally accepted as $D$ for the present track. The reason for this is that the present track may be dominated by the off-nadir observations, thus it is difficult to get a reasonable $D$ if only this track is processed. Therefore, all observations of all tracks over the lake are considered.

For example, Figure 5 shows the calculation of $D$ for the track over Ngoring Lake in Figure 3a. Because the D1 (200 m; Figure 5a) from the present track is less than D2 (400 m; Figure 5b) from all tracks, $D$ of this track is determined as the minimum of $D 1$ and $D 2(200 \mathrm{~m})$. From Figures $3 \mathrm{a}$ and $5 \mathrm{c}$, it is seen that the off-nadir observations have been removed effectively. 

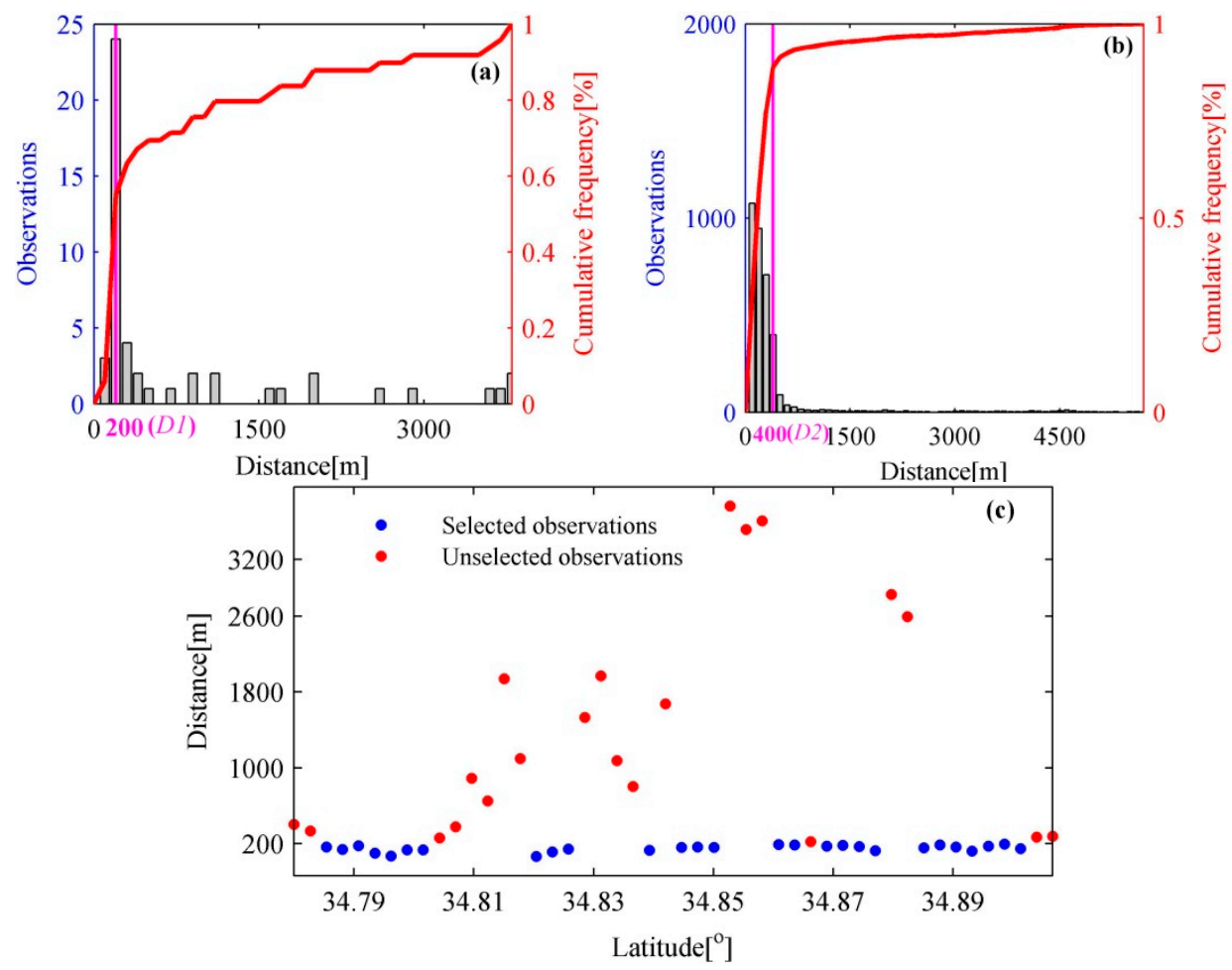

Figure 5. (a) Cumulative distribution function (CDF) and D1 from the track in Figure 3a. (b) CDF and D2 from all tracks over Ngoring Lake. Magenta lines represent the locations of D1 and D2. (c) The selected results.

Second, Tbase corresponding to each threshold Thres was calculated for each track. Thres is a percentage of the maximum power of the waveform and takes a value of 0.20 to 0.80 in steps of 0.10 . Each Tbase represents a stable height and can be expressed as

$$
H_{q}^{o f f}=\text { Tbase }+\sigma_{o b s} \epsilon_{q}
$$

where $H_{q}^{o f f}$ is the peak height of the $q$-th selected observation, $\sigma_{o b s}$ is a scaling parameter, $\sigma_{o b s} \epsilon_{q}$ is the observation noise term, and $\epsilon_{q}$ follows a mixture of Gaussian and Cauchy distributions [18]. Tbase and $\sigma_{o b s}$ were obtained by maximum-likelihood estimation for all selected observations. Here, the peak height represents a bin height corresponding to the first peak that exceeds Thres of the maximum power. Figure 6 shows the peak heights at different Thres for two tracks.

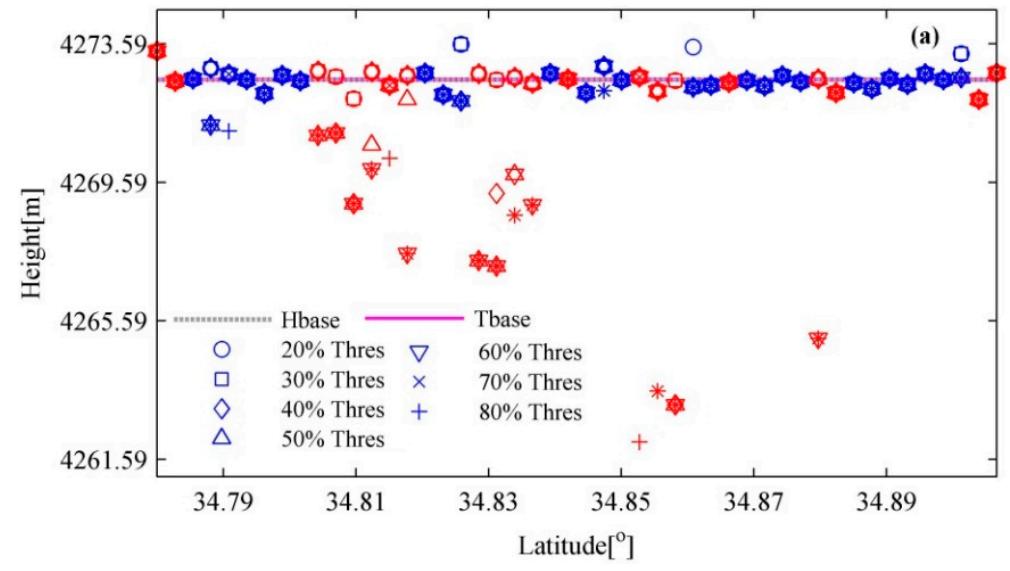

Figure 6. Cont. 


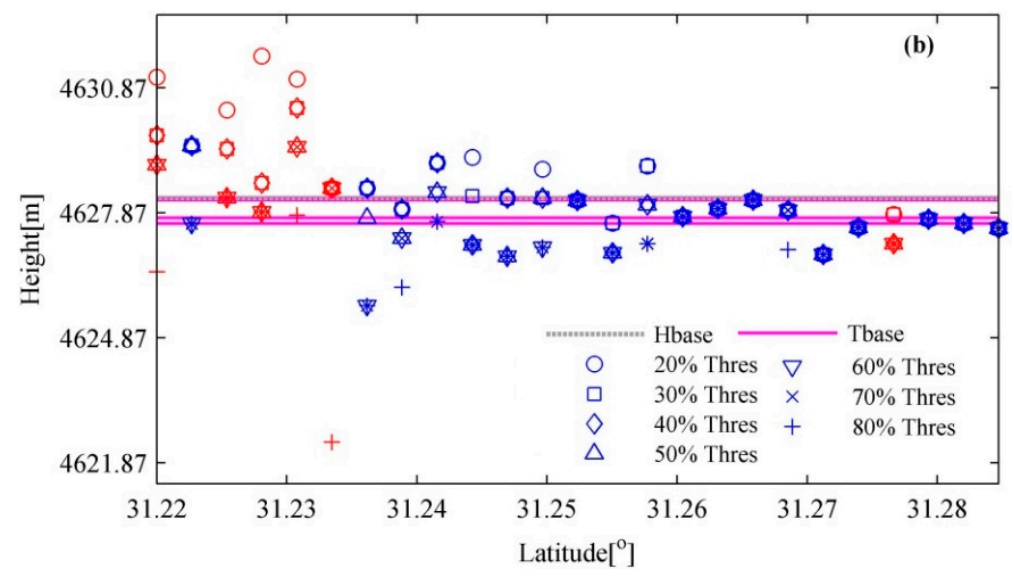

Figure 6. (a) All peak heights for the track over Ngoring Lake on 5 June 2011. (b) All peak heights for the track over Dawa Co on 30 December 2014. Blue and red symbols represent the selected and removed observations, respectively.

Third, Hbase was calculated. For each track, when the standard deviation of all Tbase is less than $0.10 \mathrm{~m}$, the average of all Tbase is taken as Hbase. In this case, all peak heights at different Thres were very close (see Figure 6a), accounting for $89 \%$ of all processed tracks. However, when the standard deviation of all Tbase is more than $0.10 \mathrm{~m}$, the peak heights at different Thres may vary greatly (see Figure $6 \mathrm{~b}$ ). Because the noise is greatly reduced by the previous steps, the first stable signal reflected by the selected observations can represent the water surface. In this case, the maximum of all Tbase was accepted as Hbase, accounting for $11 \%$ of all processed tracks. It should be noted that the optimal Thres relies on the shape of the along-track waveforms rather than the lake area.

\section{Results and Discussion}

\subsection{Comparison of Retracking Methods}

\subsubsection{Multi-Peak Waveform Processing}

The performance of ImpMWaPP was evaluated by comparing it to those of five existing algorithms: (i) The Narrow Primary Peak Threshold retracker (NPPTR) with a 50\% threshold level (NPPTR[0.5]) [28], (ii) NPPTR with an 80\% threshold level (NPPTR[0.8]) [28], (iii) the Narrow Primary Peak OCOG Retracker (NPPOR) [28], (iv) the MWaPP retracker [17], and (v) ESAL2 [29].

Figure 7 shows the retracked results for four waveforms corresponding to spots 1, 5, 8, and 9 in Figure 3a. It is clear that ImpMWaPP handles all the waveforms successfully, showing it to be highly adept at processing multi-peak waveforms. However, MWaPP, NPPTR[0.5], NPPTR[0.8], and NPPOR fail to determine the leading edge of the water reflection for the waveform of spot 9 (Figure 7d), and ESAL2 fails to properly process the echo of spot 5 (Figure $7 \mathrm{~b}$ ). Figure $7 \mathrm{~d}$ also shows that MWaPP is seriously influenced by a larger noise in front of the water signal in the waveform compared to ImpMWaPP.

\subsubsection{Comparison of Along-Track Water Levels}

To illustrate the advantages of ImpMWaPP, the results for a track over Bamco are shown in Figure 8. From Figure 8a,b, this track includes many near-shore and off-nadir observations with complex echoes. From Figure $8 c$, the water levels derived by ImpMWaPP are stable, whereas those derived by the other retrackers vary largely, especially in the near-shore and off-nadir spots. The standard deviations of the water levels derived by the different retrackers are $1.17 \mathrm{~m}$ (ESAL2), $0.62 \mathrm{~m}$ (MWaPP), $1.24 \mathrm{~m}$ (NPPTR[0.5]), $1.25 \mathrm{~m}$ (NPPTR[0.8]), $1.24 \mathrm{~m}$ (NPPOR), and $0.23 \mathrm{~m}$ (ImpMWaPP). 

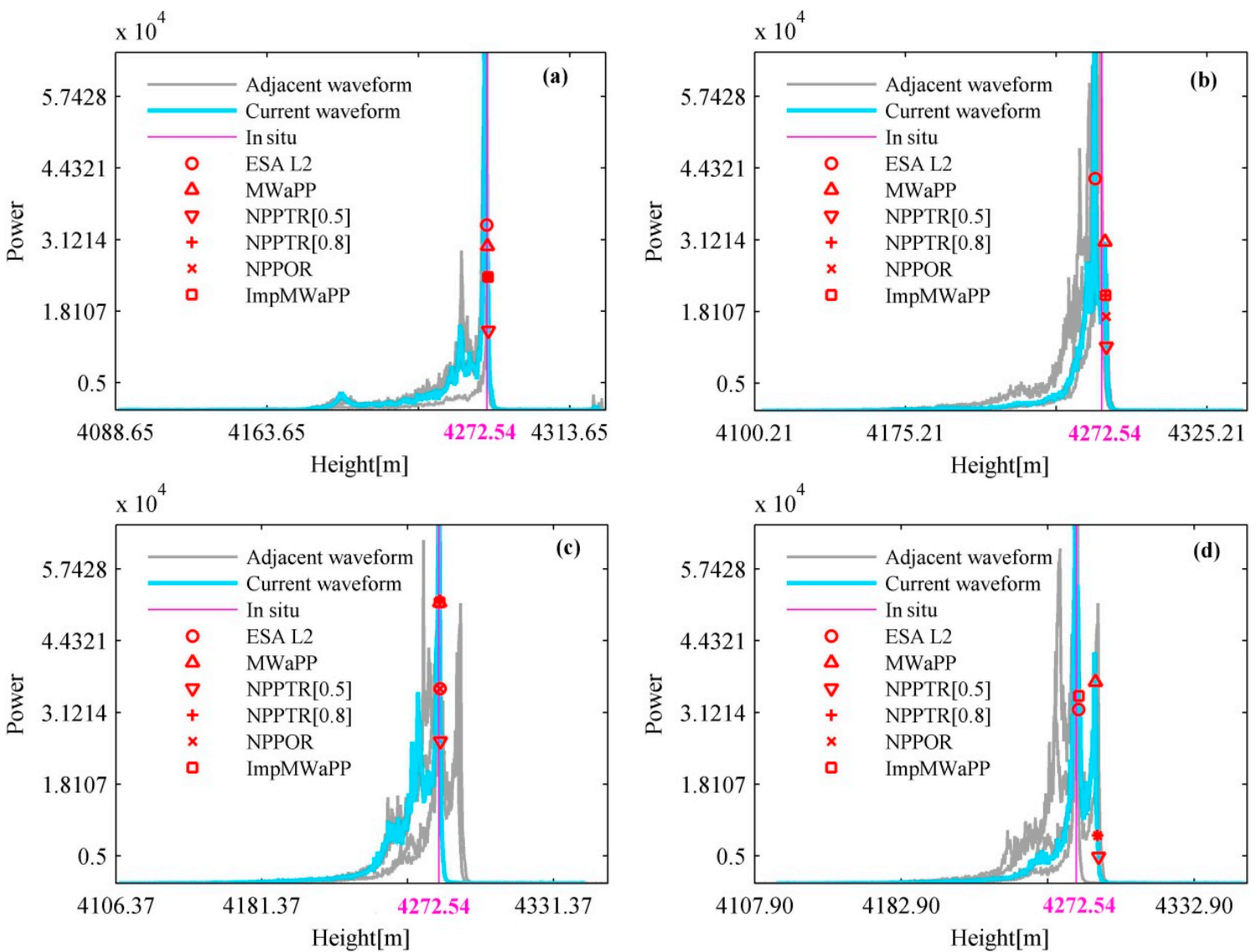

Figure 7. Retracked results for four waveforms corresponding to spots (a) 1, (b) 5, (c) 8, and (d) 9 in Figure 3a. Magenta numbers represent the values of the in situ water levels.

It should be noted that the absence of some results in Figure $8 \mathrm{c}$ is because of the removal of abnormal water levels greater than $4575 \mathrm{~m}$, which occurred mainly for MWaPP, NPPTR[0.5], NPPTR[0.8], and NPPOR. However, ImpMWaPP can handle more observations effectively.
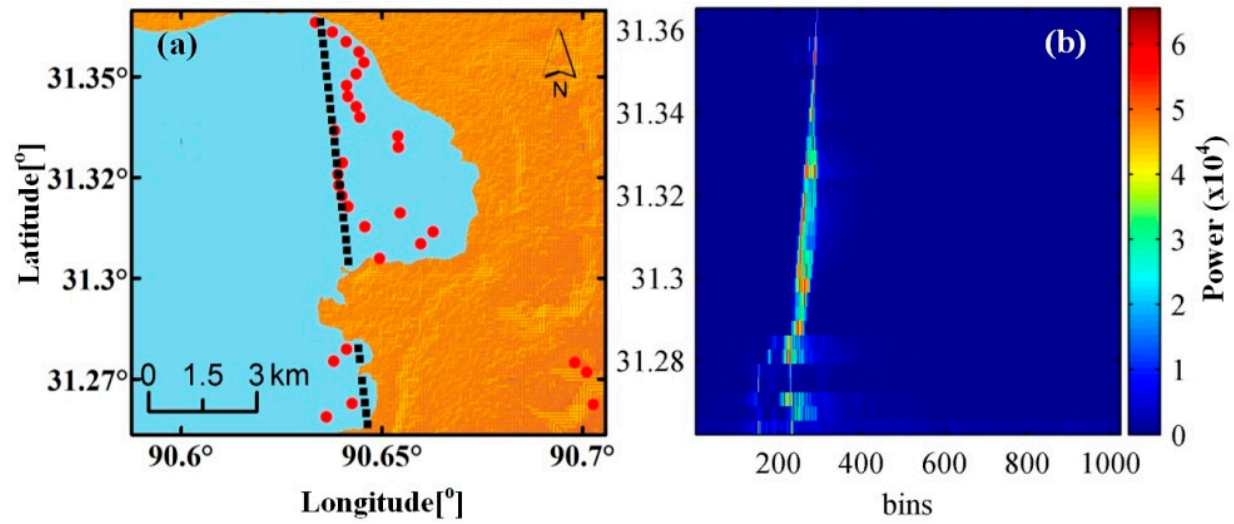

Figure 8. Cont. 


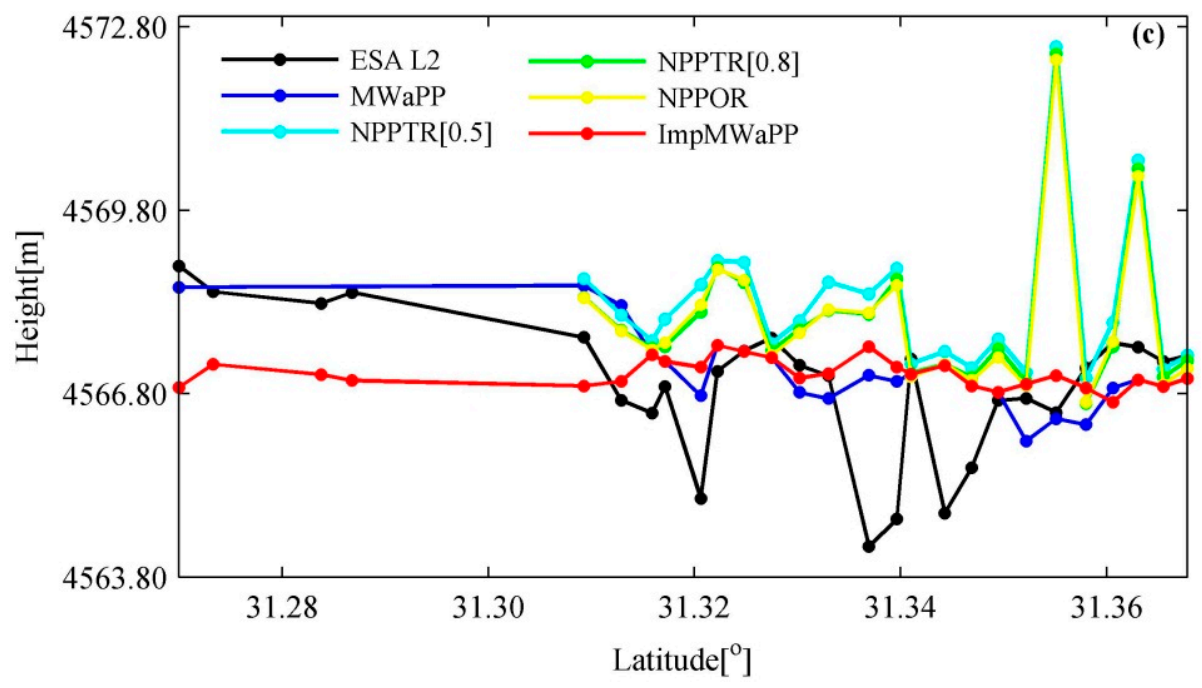

Figure 8. (a) Track over Bamco on 4 May 2014 (black and red solid points mark the nadir and corresponding Level-2 positions, respectively), (b) corresponding waveforms, and (c) retracked water levels.

\subsection{Time Series}

Table 2 gives the root-mean-squared errors (RMSEs) for the seven lakes between the Cryosat- 2 time series and the in situ data. The abnormal track mean levels that have been removed, and the statistical results of the track mean levels used for the Cryosat-2 time series, are shown in Appendix A. It can be seen that ImpMWaPP provides excellent results for all the lakes and has the best results for four lakes (Qinghai Lake, Nam Co, Ngoring Lake, and Longyangxia). Compared to the other retrackers, ImpMWaPP also has the lowest mean RMSE $(0.175 \mathrm{~m})$ for all the lakes. In addition, for Qinghai Lake, the RMSE from ImpMWaPP is better than the RMSE of $0.093 \mathrm{~m}$ derived from the Cryosat-2 LR mode data given by Reference [25]; and for Nam Co, the RMSE from this retracker is also better than the RMSE of $0.18 \mathrm{~m}$ given by Reference [30].

Table 2. Root-mean-squared errors (RMSEs) for the seven lakes between the Cryosat-2 time series and the in situ data.

\begin{tabular}{ccccccc}
\hline Lake Name & ESAL2 & MWaPP & NPPTR[0.5] & NPPTR[0.8] & NPPOR & ImpMWaPP \\
\hline \multirow{2}{*}{ Qinghai Lake } & $0.113 \mathrm{~m}$ & $0.092 \mathrm{~m}$ & $0.096 \mathrm{~m}$ & $0.121 \mathrm{~m}$ & $0.114 \mathrm{~m}$ & $0.085 \mathrm{~m}$ \\
& {$[48,48]$} & {$[49,49]$} & {$[48,48]$} & {$[48,48]$} & {$[46,46]$} & {$[49,49]$} \\
\hline \multirow{2}{*}{ Nam Co } & $0.094 \mathrm{~m}$ & $0.094 \mathrm{~m}$ & $0.240 \mathrm{~m}$ & $0.159 \mathrm{~m}$ & $0.213 \mathrm{~m}$ & $0.093 \mathrm{~m}$ \\
& {$[78,36]$} & {$[78,36]$} & {$[78,36]$} & {$[78,36]$} & {$[78,36]$} & {$[79,36]$} \\
\hline \multirow{2}{*}{ Zhari Namco } & $0.120 \mathrm{~m}$ & $0.106 \mathrm{~m}$ & $0.254 \mathrm{~m}$ & $0.192 \mathrm{~m}$ & $0.257 \mathrm{~m}$ & $0.109 \mathrm{~m}$ \\
& {$[58,50]$} & {$[59,51]$} & {$[57,49]$} & {$[58,50]$} & {$[57,49]$} & {$[59,51]$} \\
\hline \multirow{2}{*}{ Ngoring Lake } & $0.314 \mathrm{~m}$ & $0.289 \mathrm{~m}$ & $0.241 \mathrm{~m}$ & $0.164 \mathrm{~m}$ & $0.189 \mathrm{~m}$ & $0.159 \mathrm{~m}$ \\
& {$[58,58]$} & {$[58,58]$} & {$[58,58]$} & {$[58,58]$} & {$[58,58]$} & {$[58,58]$} \\
\hline \multirow{2}{*}{ Longyangxia } & $3.701 \mathrm{~m}$ & $0.871 \mathrm{~m}$ & $0.930 \mathrm{~m}$ & $0.951 \mathrm{~m}$ & $0.921 \mathrm{~m}$ & $0.573 \mathrm{~m}$ \\
& {$[5,5]$} & {$[5,5]$} & {$[5,5]$} & {$[5,5]$} & {$[5,5]$} & {$[5,5]$} \\
\hline \multirow{2}{*}{ Bamco } & $0.397 \mathrm{~m}$ & $0.079 \mathrm{~m}$ & $0.251 \mathrm{~m}$ & $0.156 \mathrm{~m}$ & $0.210 \mathrm{~m}$ & $0.087 \mathrm{~m}$ \\
& {$[7,5]$} & {$[7,5]$} & {$[7,6]$} & {$[8,6]$} & {$[8,6]$} & {$[8,6]$} \\
\hline \multirow{2}{*}{ Dawa Co } & $0.112 \mathrm{~m}$ & $0.146 \mathrm{~m}$ & $0.128 \mathrm{~m}$ & $0.105 \mathrm{~m}$ & $0.143 \mathrm{~m}$ & $0.122 \mathrm{~m}$ \\
& {$[5,5]$} & {$[6,5]$} & {$[5,4]$} & {$[6,5]$} & {$[6,5]$} & {$[6,5]$} \\
\hline
\end{tabular}

The two values in each pair of square bracket are the counts for the lake levels retrieved from the Cryosat-2 time series data and the in situ water levels, respectively. Because of the discontinuity of the in situ data in some lakes, these two counts are not always consistent.

Except for Longyangxia and Ngoring Lake, the results derived by MWaPP for the other lakes are similar compared to those from ImpMWaPP. Generally, ImpMWaPP and MWaPP give better results 
than do the other retrackers. Additionally, compared to the other retrackers, the number of valid epochs in the Cryosat-2 time series obtained by ImpMWaPP is slightly higher, which is also beneficial for monitoring the water level of lakes with sparse observations.

The Cryosat-2 time series for four lakes and the in situ data is shown in Figure 9. For all four lakes, the time series derived by ImpMWaPP agree well with the in situ data. MWaPP and ESAL2 also show good results for Qinghai Lake, Nam Co, and Zhari Namco; however, for Ngoring Lake, because many observations with weak water signals are not handled effectively, the deviations between the Cryosat-2 time series derived by these two retrackers and the in situ data are large in some epochs. In addition, because of the inability to effectively handle the waveforms with high land noise in front of the water signal, the results from NPPTR[0.5], NPPTR[0.8], and NPPOR for Zhari Namco are the worst.

Figure 10 shows the spatial distribution of the deviations between the Cryosat-2 time series for Ngoring Lake and the in situ data. The results reveal that ImpMWaPP performs the best, with most of the deviations by this retracker being less than $0.30 \mathrm{~m}$. However, in many ice-surface and narrow-water tracks, the results derived by MWaPP and ESAL2 all exceed $0.30 \mathrm{~m}$. Compared to NPPTR[0.5] and NPPOR, NPPTR[0.8] gives significantly better results, but still slightly worse than those from ImpMWaPP.

\subsection{Time Series of Icing and No-Ice Periods}

A retracker's ability is affected by the freezing of lake water [7,31]. Because most lakes covered by the Cryosat-2 SARin data ice over during winter, the abilities of the different retrackers during icing and no-ice periods were explored. The two periods are defined by regular dates in Section 2.1. Tables 3 and 4 give the RMSEs for four lakes between the Cryosat-2 time series in the icing and no-ice periods, respectively, and the in situ data. For MWaPP and ESAL2, most of the results in the no-ice period are better than those in the icing period, and the results in both periods derived by ImpMWaPP are all excellent. Meanwhile, except for Ngoring Lake, NPPTR[0.5], NPPTR[0.8], and NPPOR achieve significantly worse results in the no-ice period than do the other retrackers. Therefore, we suggest that ImpMWaPP should be used to handle the Cryosat-2 SARin data for lakes that ice over in winter.

\subsection{Along-Track Standard Deviations}

To further compare the different retrackers, Table 5 lists the mean and median of all track standard deviations for each retracker over each lake. It is seen that ImpMWaPP has the lowest results over all lakes, showing that the water levels derived by ImpMWaPP are the most stable. In general, NPPTR[0.5], NPPTR[0.8], and NPPOR give similar results, but are worse than the other retrackers.

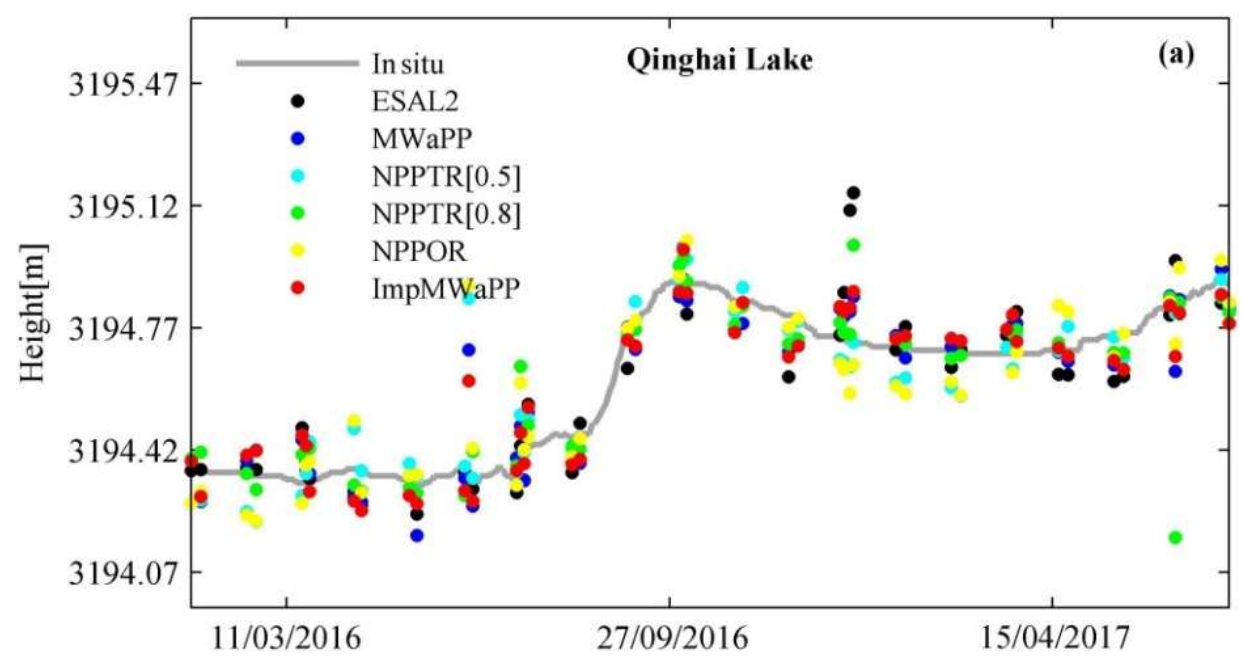

Figure 9. Cont. 

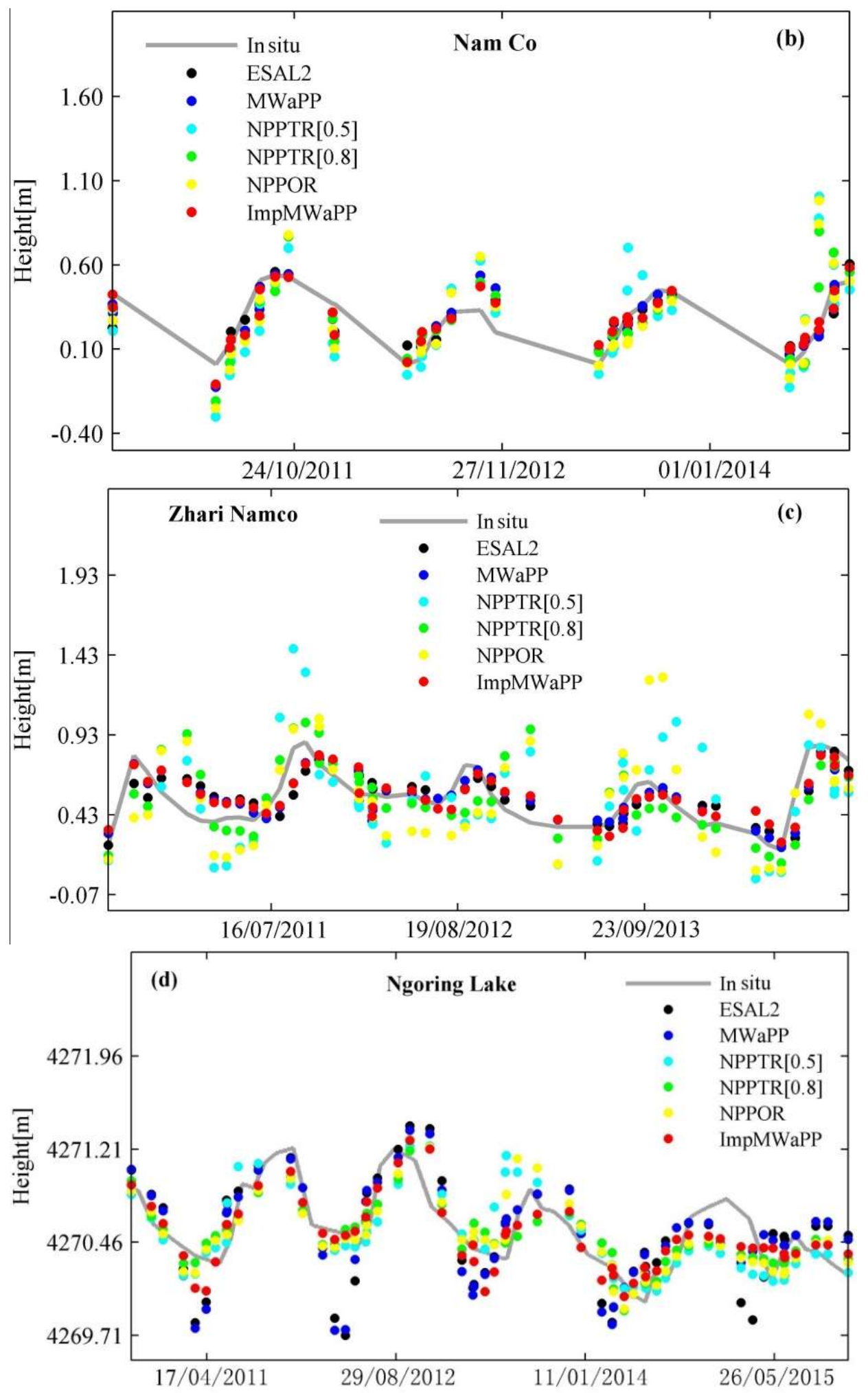

Figure 9. Cryosat-2 time series for four lakes obtained from different retrackers and compared with the in situ data: (a) Qinghai Lake; (b) Nam Co; (c) Zhari Namco; (d) Ngoring Lake. 


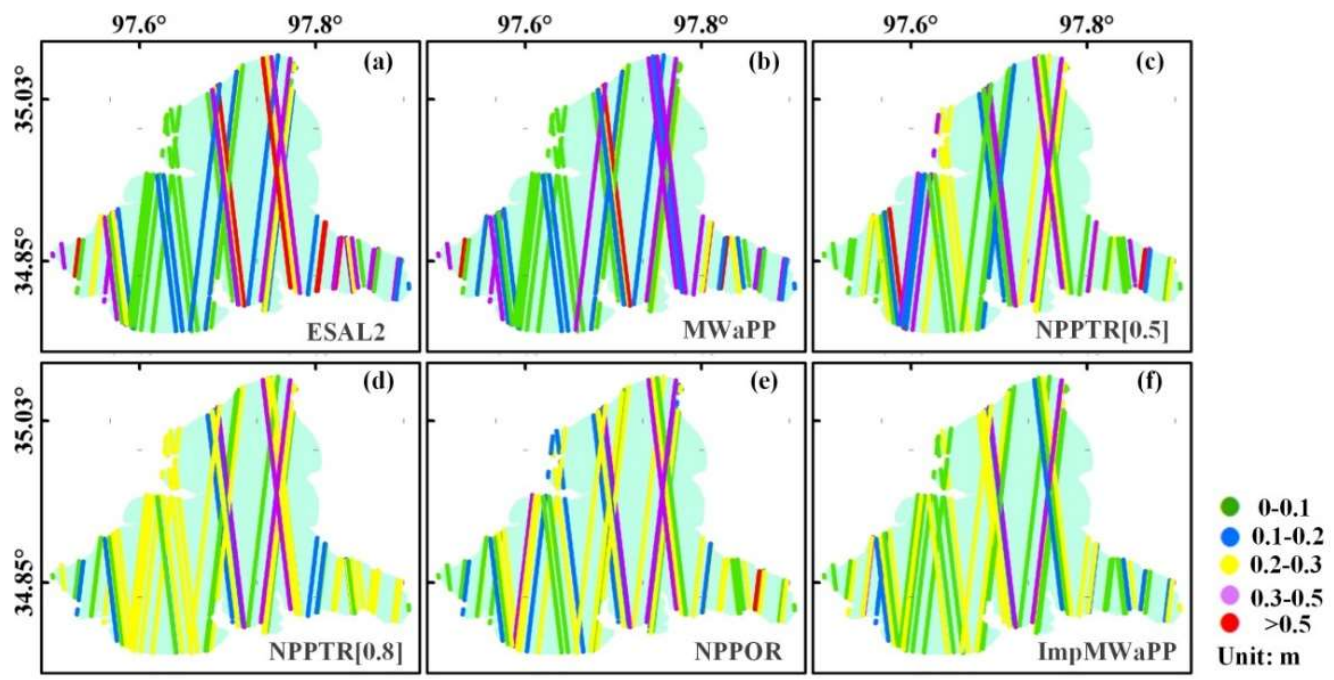

Figure 10. Spatial distribution of deviations between Cryosat-2 time series for Ngoring derived from different retrackers and in situ data: (a) ESAL2; (b) MWaPP; (c) NPPTR[0.5]; (d) NPPTR[0.8]; (e) NPPOR; (f) ImpMWaPP.

Table 3. RMSEs between Cryosat-2 time series and in situ data: icing period.

\begin{tabular}{ccccccc}
\hline Lake Name & ESAL2 & MWaPP & NPPTR[0.5] & NPPTR[0.8] & NPPOR & ImpMWaPP \\
\hline \multirow{2}{*}{ Qinghai Lake } & $0.138 \mathrm{~m}$ & $0.073 \mathrm{~m}$ & $0.078 \mathrm{~m}$ & $0.075 \mathrm{~m}$ & $0.094 \mathrm{~m}$ & $0.079 \mathrm{~m}$ \\
& {$[23]$} & {$[23]$} & {$[23]$} & {$[23]$} & {$[22]$} & {$[23]$} \\
\hline \multirow{2}{*}{ Nam Co } & $0.133 \mathrm{~m}$ & $0.136 \mathrm{~m}$ & $0.276 \mathrm{~m}$ & $0.170 \mathrm{~m}$ & $0.217 \mathrm{~m}$ & $0.131 \mathrm{~m}$ \\
& {$[2]$} & {$[2]$} & {$[2]$} & {$[2]$} & {$[2]$} & {$[2]$} \\
\hline \multirow{2}{*}{ Zhari Namco } & $0.126 \mathrm{~m}$ & $0.120 \mathrm{~m}$ & $0.264 \mathrm{~m}$ & $0.228 \mathrm{~m}$ & $0.239 \mathrm{~m}$ & $0.111 \mathrm{~m}$ \\
& {$[14]$} & {$[14]$} & {$[14]$} & {$[14]$} & {$[14]$} & {$[14]$} \\
\hline \multirow{2}{*}{ Ngoring Lake } & $0.402 \mathrm{~m}$ & $0.370 \mathrm{~m}$ & $0.182 \mathrm{~m}$ & $0.168 \mathrm{~m}$ & $0.168 \mathrm{~m}$ & $0.156 \mathrm{~m}$ \\
& {$[23]$} & {$[23]$} & {$[23]$} & {$[23]$} & {$[23]$} & {$[23]$} \\
\hline
\end{tabular}

Value in square brackets is the number of in situ water levels for that calculation.

Table 4. RMSEs between Cryosat-2 time series and in situ data: no-ice period.

\begin{tabular}{ccccccc}
\hline Lake Name & ESAL2 & MWaPP & NPPTR[0.5] & NPPTR[0.8] & NPPOR & ImpMWaPP \\
\hline \multirow{2}{*}{ Qinghai Lake } & $0.083 \mathrm{~m}$ & $0.107 \mathrm{~m}$ & $0.111 \mathrm{~m}$ & $0.152 \mathrm{~m}$ & $0.130 \mathrm{~m}$ & $0.089 \mathrm{~m}$ \\
& {$[25]$} & {$[26]$} & {$[25]$} & {$[25]$} & {$[24]$} & {$[26]$} \\
\hline \multirow{2}{*}{ Nam Co } & $0.091 \mathrm{~m}$ & $0.091 \mathrm{~m}$ & $0.237 \mathrm{~m}$ & $0.159 \mathrm{~m}$ & $0.213 \mathrm{~m}$ & $0.091 \mathrm{~m}$ \\
& {$[34]$} & {$[34]$} & {$[34]$} & {$[34]$} & {$[34]$} & {$[34]$} \\
\hline \multirow{2}{*}{ Zhari Namco } & $0.118 \mathrm{~m}$ & $0.096 \mathrm{~m}$ & $0.251 \mathrm{~m}$ & $0.175 \mathrm{~m}$ & $0.263 \mathrm{~m}$ & $0.104 \mathrm{~m}$ \\
& {$[36]$} & {$[37]$} & {$[35]$} & {$[36]$} & {$[35]$} & {$[37]$} \\
\hline \multirow{2}{*}{ Ngoring Lake } & $0.239 \mathrm{~m}$ & $0.219 \mathrm{~m}$ & $0.273 \mathrm{~m}$ & $0.161 \mathrm{~m}$ & $0.201 \mathrm{~m}$ & $0.161 \mathrm{~m}$ \\
& {$[35]$} & {$[35]$} & {$[35]$} & {$[35]$} & {$[35]$} & {$[35]$} \\
\hline
\end{tabular}


Table 5. Means and medians of track standard deviations derived by the different retrackers over the seven lakes.

\begin{tabular}{ccccccc}
\hline Lake Name & ESAL2 & MWaPP & NPPTR[0.5] & NPPTR[0.8 $]$ & NPPOR & ImpMWaPP \\
\hline \multirow{2}{*}{ Qinghai Lake } & $0.170 \mathrm{~m}$ & $0.145 \mathrm{~m}$ & $0.413 \mathrm{~m}$ & $0.394 \mathrm{~m}$ & $0.396 \mathrm{~m}$ & $0.098 \mathrm{~m}$ \\
& {$[0.116 \mathrm{~m}]$} & {$[0.092 \mathrm{~m}]$} & {$[0.401 \mathrm{~m}]$} & {$[0.366 \mathrm{~m}]$} & {$[0.379 \mathrm{~m}]$} & {$[0.084 \mathrm{~m}]$} \\
\hline \multirow{2}{*}{ Nam Co } & $0.251 \mathrm{~m}$ & $0.246 \mathrm{~m}$ & $0.490 \mathrm{~m}$ & $0.479 \mathrm{~m}$ & $0.472 \mathrm{~m}$ & $0.208 \mathrm{~m}$ \\
& {$[0.137 \mathrm{~m}]$} & {$[0.156 \mathrm{~m}]$} & {$[0.457 \mathrm{~m}]$} & {$[0.422 \mathrm{~m}]$} & {$[0.446 \mathrm{~m}]$} & {$[0.102 \mathrm{~m}]$} \\
\hline \multirow{2}{*}{ Zhari Namco } & $0.213 \mathrm{~m}$ & $0.241 \mathrm{~m}$ & $0.674 \mathrm{~m}$ & $0.636 \mathrm{~m}$ & $0.618 \mathrm{~m}$ & $0.108 \mathrm{~m}$ \\
& {$[0.158 \mathrm{~m}]$} & {$[0.157 \mathrm{~m}]$} & {$[0.502 \mathrm{~m}]$} & {$[0.463 \mathrm{~m}]$} & {$[0.475 \mathrm{~m}]$} & {$[0.105 \mathrm{~m}]$} \\
\hline \multirow{2}{*}{ Ngoring Lake } & $0.256 \mathrm{~m}$ & $0.239 \mathrm{~m}$ & $0.267 \mathrm{~m}$ & $0.254 \mathrm{~m}$ & $0.254 \mathrm{~m}$ & $0.129 \mathrm{~m}$ \\
& {$[0.122 \mathrm{~m}]$} & {$[0.105 \mathrm{~m}]$} & {$[0.216 \mathrm{~m}]$} & {$[0.229 \mathrm{~m}]$} & {$[0.217 \mathrm{~m}]$} & {$[0.097 \mathrm{~m}]$} \\
\hline \multirow{2}{*}{ Longyangxia } & $0.668 \mathrm{~m}$ & $0.295 \mathrm{~m}$ & $0.532 \mathrm{~m}$ & $0.464 \mathrm{~m}$ & $0.519 \mathrm{~m}$ & $0.126 \mathrm{~m}$ \\
& {$[0.442 \mathrm{~m}]$} & {$[0.098 \mathrm{~m}]$} & {$[0.622 \mathrm{~m}]$} & {$[0.350 \mathrm{~m}]$} & {$[0.608 \mathrm{~m}]$} & {$[0.089 \mathrm{~m}]$} \\
\hline \multirow{2}{*}{ Bamco } & $0.389 \mathrm{~m}$ & $0.461 \mathrm{~m}$ & $0.626 \mathrm{~m}$ & $0.594 \mathrm{~m}$ & $0.581 \mathrm{~m}$ & $0.178 \mathrm{~m}$ \\
& {$[0.190 \mathrm{~m}]$} & {$[0.182 \mathrm{~m}]$} & {$[0.697 \mathrm{~m}]$} & {$[0.651 \mathrm{~m}]$} & {$[0.662 \mathrm{~m}]$} & {$[0.127 \mathrm{~m}]$} \\
\hline \multirow{2}{*}{ Dawa Co } & $0.320 \mathrm{~m}$ & $0.224 \mathrm{~m}$ & $0.478 \mathrm{~m}$ & $0.461 \mathrm{~m}$ & $0.523 \mathrm{~m}$ & $0.128 \mathrm{~m}$ \\
& {$[0.239 \mathrm{~m}]$} & {$[0.163 \mathrm{~m}]$} & {$[0.480 \mathrm{~m}]$} & {$[0.487 \mathrm{~m}]$} & {$[0.492 \mathrm{~m}]$} & {$[0.110 \mathrm{~m}]$} \\
\hline
\end{tabular}

Medians are written in square brackets.

\section{Conclusions}

In this study, a modified retracker (ImpMWaPP) for Cryosat-2 SARin waveforms was proposed that can effectively process multi-peak waveforms over inland water. ImpMWaPP is not a pure single-waveform retracker, and it's core function is to obtain a reference water level using a robust statistical method and to identify the water-surface signal of the waveform based on this reference water level. We tested the retracking performance of six algorithms for Cryosat-2 SARin waveforms in comparison to the in situ data of seven Tibetan Plateau lakes with different characteristics. The six algorithms used in this study were ImpMWaPP, ESAL2, MWaPP, NPPTR[0.5], NPPTR[0.8], and NPPOR.

The results reveal that ImpMWaPP outperforms the other algorithms in handling multi-peak waveforms from the Cryosat-2 SARin mode. As a result, the Cryosat-2 time series obtained by ImpMWaPP has good precision and slightly more epochs, which is positive for monitoring lakes with sparse data. Additionally, ImpMWaPP has good performance for lakes during icing and no-ice periods, and is more suitable for lakes that ice over in winter. However, the disadvantage of this algorithm is that the observation position must be relocated, and the relocated position can be obtained from Cryosat-2 SARin Level-2 data. In addition, the other algorithms also have their own advantages. First, for less affected observations, high-precision lake levels can be obtained directly from the Cryosat-2 Level-2 Baseline $C$ data products with no additional computation. Second, MWaPP can give quite accurate water levels using observations from the no-ice period.

Finally, it remains necessary to rely on the superior performance of space-borne altimeters (e.g., spatial and temporal resolution) to fundamentally overcome the difficulty in monitoring the water levels of small lakes. Such altimeters include the three-dimensional imaging microwave altimeter carried by the Tiangong- 2 space laboratory and the altimeter carried by the Surface Water Ocean Topography (SWOT) satellite [32,33]. In future, they can help to better monitor lake levels.

Author Contributions: H.X. processed Cryosat-2 data, built the model, and wrote the manuscript. J.L. contributed with discussions and manuscript writing. L.Z. processed Cryosat-2 data.

Funding: This research was supported by the National Key Research and Development Program of China (2016YFB0501501), and the National Natural Science Foundation of China (41871256).

Acknowledgments: We thank the ESA for providing the Cryosat-2 SARin data, and the Hydrology and Water Resources Survey Bureau in Qinghai Province, the Yellow River Commission of the Ministry of Water Resources, and the Institute of Tibetan Plateau Research, Chinese Academy of Sciences for providing the in situ data. 
Moreover, the authors are grateful to the anonymous reviewers for their constructive suggestions to improve this manuscript.

Conflicts of Interest: The authors declare no conflicts of interest.

\section{Appendix A}
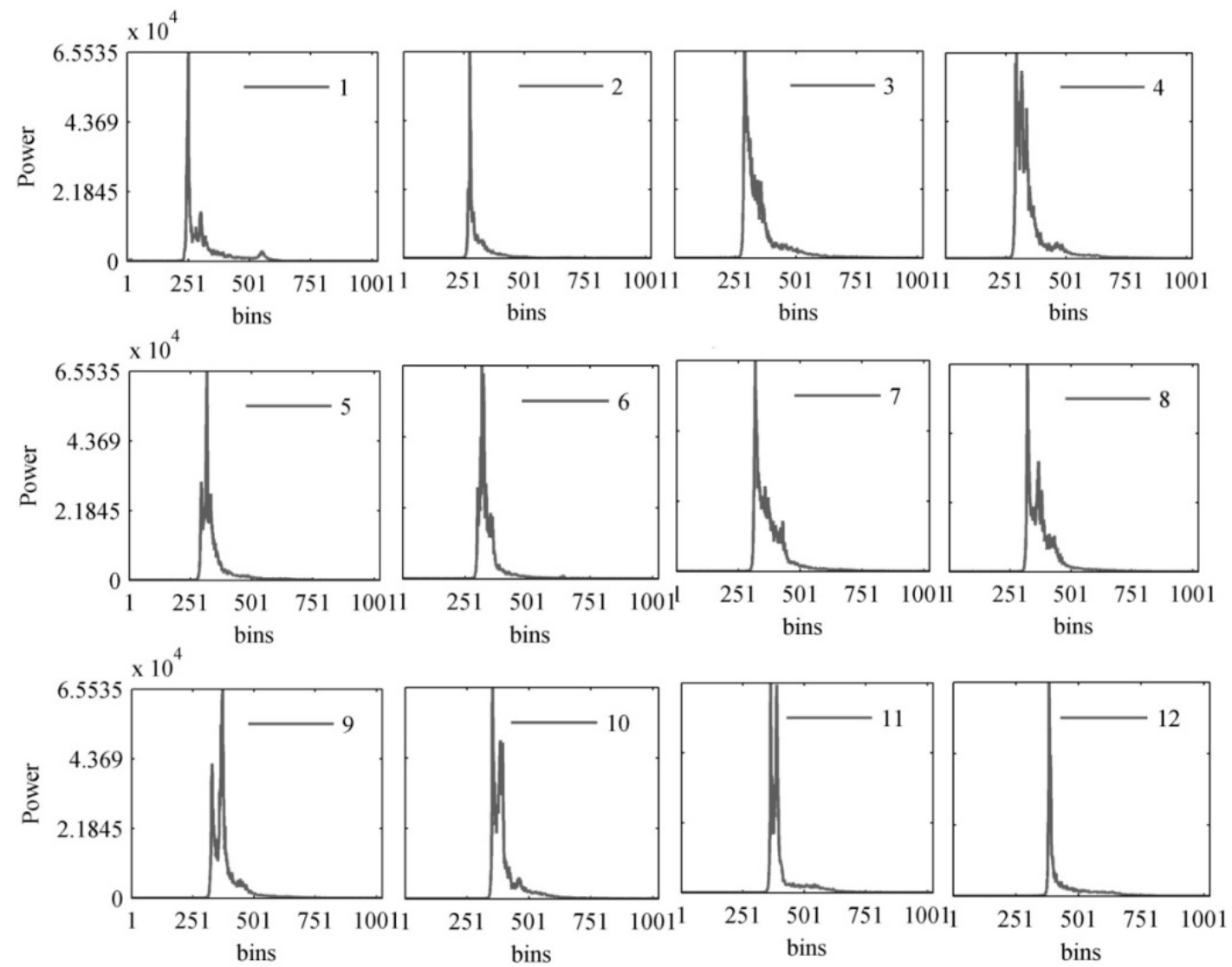

Figure A1. Waveforms at spots 1-12 corresponding to Figure $3 a$.

Table A1. Abnormal track mean levels.

\begin{tabular}{ccccccc}
\hline Lake Name & ESAL2 & MWaPP & NPPTR[0.5] & NPPTR[0.8] & NPPOR & ImpMWaPP \\
\hline Qinghai Lake & $3196.316 \mathrm{~m}$ & - & $3197.114 \mathrm{~m}$ & $3196.246 \mathrm{~m}$ & $\begin{array}{l}3194.727 \mathrm{~m} \\
3196.446 \mathrm{~m} \\
3196.617 \mathrm{~m}\end{array}$ \\
\hline Nam Co & $5069.691 \mathrm{~m}$ & $5087.456 \mathrm{~m}$ & $5087.989 \mathrm{~m}$ & $5087.395 \mathrm{~m}$ & $5087.663 \mathrm{~m}$ & - \\
\hline Zhari Namco & $4949.409 \mathrm{~m}$ & - & $4617.650 \mathrm{~m}$ & $4982.618 \mathrm{~m}$ & $4617.647 \mathrm{~m}$ & - \\
\hline Ngoring Lake & - & - & $-4982.154 \mathrm{~m}$ & - & - & - \\
\hline Longyangxia & - & - & - & - & - & - \\
\hline Bamco & $4646.898 \mathrm{~m}$ & $4706.849 \mathrm{~m}$ & $4569.472 \mathrm{~m}$ & - & - & - \\
\hline Dawa Co & $4626.380 \mathrm{~m}$ & - & $4629.480 \mathrm{~m}$ & - & - \\
\hline
\end{tabular}


Table A2. Mean and standard deviation of track mean levels used for the Cryosat-2 time series derived by each retracker over each lake.

\begin{tabular}{ccccccc}
\hline Lake Name & ESAL2 & MWaPP & NPPTR[0.5] & NPPTR[0.8 $]$ & NPPOR & ImpMWaPP \\
\hline \multirow{2}{*}{ Qinghai Lake } & $3195.919 \mathrm{~m}$ & $3195.552 \mathrm{~m}$ & $3195.903 \mathrm{~m}$ & $3195.695 \mathrm{~m}$ & $3195.657 \mathrm{~m}$ & $3195.539 \mathrm{~m}$ \\
& {$[0.24 \mathrm{~m}]$} & {$[0.22 \mathrm{~m}]$} & {$[0.22 \mathrm{~m}]$} & {$[0.22 \mathrm{~m}]$} & {$[0.23 \mathrm{~m}]$} & {$[0.22 \mathrm{~m}]$} \\
\hline \multirow{2}{*}{ NamCo } & $4726.067 \mathrm{~m}$ & $4725.733 \mathrm{~m}$ & $4726.235 \mathrm{~m}$ & $4725.955 \mathrm{~m}$ & $4725.968 \mathrm{~m}$ & $4725.715 \mathrm{~m}$ \\
& {$[0.30 \mathrm{~m}]$} & {$[0.33 \mathrm{~m}]$} & {$[0.46 \mathrm{~m}]$} & {$[0.36 \mathrm{~m}]$} & {$[0.43 \mathrm{~m}]$} & {$[0.32 \mathrm{~m}]$} \\
\hline \multirow{2}{*}{ Zhari Namco } & $4615.237 \mathrm{~m}$ & $4614.912 \mathrm{~m}$ & $4615.467 \mathrm{~m}$ & $4615.149 \mathrm{~m}$ & $4615.185 \mathrm{~m}$ & $4614.892 \mathrm{~m}$ \\
& {$[0.17 \mathrm{~m}]$} & {$[0.18 \mathrm{~m}]$} & {$[0.49 \mathrm{~m}]$} & {$[0.35 \mathrm{~m}]$} & {$[0.49 \mathrm{~m}]$} & {$[0.17 \mathrm{~m}]$} \\
\hline \multirow{2}{*}{ Ngoring Lake } & $4272.831 \mathrm{~m}$ & $4272.532 \mathrm{~m}$ & $4273.130 \mathrm{~m}$ & $4272.834 \mathrm{~m}$ & $4272.625 \mathrm{~m}$ & $4272.837 \mathrm{~m}$ \\
& {$[0.53 \mathrm{~m}]$} & {$[0.51 \mathrm{~m}]$} & {$[0.42 \mathrm{~m}]$} & {$[0.36 \mathrm{~m}]$} & {$[0.38 \mathrm{~m}]$} & {$[0.32 \mathrm{~m}]$} \\
\hline \multirow{2}{*}{ Longyangxia } & $2576.587 \mathrm{~m}$ & $2573.791 \mathrm{~m}$ & $2574.390 \mathrm{~m}$ & $2574.180 \mathrm{~m}$ & $2574.122 \mathrm{~m}$ & $2573.583 \mathrm{~m}$ \\
& {$[1.76 \mathrm{~m}]$} & {$[4.12 \mathrm{~m}]$} & {$[4.43 \mathrm{~m}]$} & {$[4.38 \mathrm{~m}]$} & {$[4.44 \mathrm{~m}]$} & {$[3.99 \mathrm{~m}]$} \\
\hline \multirow{2}{*}{ Bamco } & $4567.314 \mathrm{~m}$ & $4567.085 \mathrm{~m}$ & $4567.479 \mathrm{~m}$ & $4567.296 \mathrm{~m}$ & $4567.190 \mathrm{~m}$ & $4567.094 \mathrm{~m}$ \\
& {$[0.36 \mathrm{~m}]$} & {$[0.11 \mathrm{~m}]$} & {$[0.24 \mathrm{~m}]$} & {$[0.17 \mathrm{~m}]$} & {$[0.21 \mathrm{~m}]$} & {$[0.15 \mathrm{~m}]$} \\
\hline \multirow{2}{*}{ Dawa Co } & 4627.790 & $4627.543 \mathrm{~m}$ & $4627.723 \mathrm{~m}$ & $4627.640 \mathrm{~m}$ & $4627.582 \mathrm{~m}$ & $4627.429 \mathrm{~m}$ \\
& {$[0.21 \mathrm{~m}]$} & {$[0.41 \mathrm{~m}]$} & {$[0.22 \mathrm{~m}]$} & {$[0.290 \mathrm{~m}]$} & {$[0.31 \mathrm{~m}]$} & {$[0.28 \mathrm{~m}]$} \\
\hline
\end{tabular}

Standard deviations are written in square brackets.

\section{References}

1. Birkett, C.M. The contribution of TOPEX/POSEIDON to the global monitoring of climatically sensitive lakes. J. Geophys. Res. 1995, 100, 25179-25204. [CrossRef]

2. Birkett, C.M. Contribution of the Topex NASA radar altimeter to the global monitoring of large rivers and wetlands. Water Resour. Res. 2004, 34, 1223-1239. [CrossRef]

3. Berry, P.A.M. Two Decades of Inland Water Monitoring Using Satellite Radar Altimetry. In Proceedings of the Symposium on 15 Years of Progress in Radar Altimetry, Venice, Italy, 13-18 March 2006.

4. Santos da Silva, J.; Seyler, F.; Calmant, S.; Rotunno Filho, O.C.; Roux, E.; Araújo, A.A.M.; Guyot, J.L. Water level dynamics of Amazon wetlands at the watershed scale by satellite altimetry. Int. J. Remote Sens. 2012, 33, 3323-3353. [CrossRef]

5. Duan, Z.; Bastiaanssen, W.G.M. Estimating water volume variations in lakes and reservoirs from four operational satellite altimetry databases and satellite imagery data. Remote Sens. Environ. 2013, 134, 403-416. [CrossRef]

6. Tong, X.; Pang, H.; Xie, H.; Xu, X.; Li, F.; Chen, L.; Luo, X.; Liu, S.; Chen, P.; Jin, Y. Estimating water volume variations in Lake Victoria over the past 22 years using multi-mission altimetry and remotely sensed images. Remote Sens. Environ. 2016, 187, 400-413. [CrossRef]

7. Crétaux, J.-F.; Abarca-del-Río, R.; Bergé-Nguyen, M.; Arsen, A.; Drolon, V.; Clos, G.; Maisongrande, P. Lake volume monitoring from space. Surv. Geophys. 2016, 37, 269-305. [CrossRef]

8. Cretaux, J.F.; Birkett, C. Lake studies from satellite radar altimetry. C. R. Geosci. 2006, 338, 1098-1112. [CrossRef]

9. Ričko, M.; Birkett, C.M.; Carton, J.A.; Crétaux, J.-F. Intercomparison and validation of continental water level products derived from satellite radar altimetry. J. Appl. Remote Sens. 2012, 6, 061710. [CrossRef]

10. Kleinherenbrink, M.; Ditmar, P.; Lindenbergh, R. Retracking cryosat data in the sarin mode and robust lake level extraction. Remote Sens. Environ. 2014, 152, 38-50. [CrossRef]

11. Baup, F.; Frappart, F.; Maubant, J. Combining high-resolution satellite images and altimetry to estimate the volume of small lakes. Hydrol. Earth Syst. Sci. 2014, 18, 2007-2020. [CrossRef]

12. Kleinherenbrink, M.; Lindenbergh, R.C.; Ditmar, P.G. Monitoring of lake level changes on the Tibetan Plateau and Tian Shan by retracking Cryosat SARIn waveforms. J. Hydrol. 2015, 521, 119-131. [CrossRef]

13. Bouzinac, C. CryoSat Product Handbook. Available online: https:/ / earth.esa.int/documents/10174/125272/ CryoSat_Product_Handbook (accessed on 1 January 2018).

14. Jiang, L.; Nielsen, K.; Andersen, O.B.; Bauer-Gottwein, P. Monitoring recent lake level variations on the Tibetan Plateau using CryoSat-2 SARIn mode data. J. Hydrol. 2017, 544, 109-124. [CrossRef] 
15. Nielsen, K.; Stenseng, L.; Andersen, O.; Knudsen, P. The Performance and Potentials of the CryoSat-2 SAR and SARIn Modes for Lake Level Estimation. Water 2017, 9, 374. [CrossRef]

16. Raney, R.K. The Delay/Doppler Radar Altimeter. IEEE Trans. Geosci. Remote Sens. 1998, 36, 1578-1588. [CrossRef]

17. Villadsen, H.; Deng, X.; Andersen, O.B.; Stenseng, L.; Nielsen, K.; Knudsen, P. Improved inland water levels from SAR altimetry using novel empirical and physical retrackers. J. Hydrol. 2016, 537, 234-247. [CrossRef]

18. Nielsen, K.; Stenseng, L.; Andersen, O.B.; Villadsen, H.; Knudsen, P. Validation of CryoSat-2 SAR mode based lake levels. Remote Sens. Environ. 2015, 171, 162-170. [CrossRef]

19. Göttl, F.; Dettmering, D.; Müller, F.; Schwatke, C. Lake Level Estimation Based on CryoSat-2 SAR Altimetry and Multi-Looked Waveform Classification. Remote Sens. 2016, 8, 885. [CrossRef]

20. Gommenginger, C.; Thibaut, P.; Fenoglio-Marc, L.; Quartly, G.; Deng, X.; Gómez-Enri, J.; Challenor, P.; Gao, Y. Retracking altimeter waveforms near the coasts. In Coastal Altimetry; Benveniste, J., Cipollini, P., Kostianoy, A.G., Vignudelli, S., Eds.; Springer: Berlin, Germany, 2011; pp. 61-101.

21. Ganguly, D.; Chander, S.; Desai, S.; Chauhan, P. A subwaveform-based retracker for multipeak waveforms: A case study over Ukai dam/reservoir. Mar. Geod. 2015, 38, 581-596. [CrossRef]

22. Wan, W.; Long, D.; Hong, Y.; Ma, Y.; Yuan, Y.; Xiao, P.; Duan, H.; Han, Z.; Gu, X. A lake data set for the Tibetan Plateau from the 1960s, 2005, and 2014. Sci. Data 2016, 3, 160039. [CrossRef] [PubMed]

23. Scagliola, M.; Fornari, M. Main Evolutions and Expected Quality Improvements in BaselineC Level1b Products. Available online: https:/ / wiki.services.eoportal.org/tiki-download_wiki_attachment.php?attId= 3553\&page=CryoSat\%20Technical\%20Notes\&download =y (accessed on 1 January 2018).

24. Pavlis, N.K.; Holmes, S.A.; Kenyon, S.C.; Factor, J.K. The development and evaluation of the Earth Gravitational Model 2008 (EGM2008). J. Geophys. Res. Solid Earth 2012. [CrossRef]

25. Zhao, Y.; Liao, J.; Shen, G.; Zhang, X. Monitoring the water level changes in Qinghai Lake with satellite altimetry data. J. Remote Sens. 2017, 21, 633-644. (In Chinese)

26. Hwang, C.; Peng, M.F.; Ning, J.; Luo, J.; Sui, C.H. Lake level variations in China from TOPEX/poseidon altimetry: Data quality assessment and links to precipitation and ENSO. Geophys. J. Int. 2005, 161, 1-11. [CrossRef]

27. Wingham, D.; Rapley, C.; Griffiths, H. New Techniques in Satellite Altimeter Tracking Systems. In Proceedings of the 1986 International Geoscience and Remote Sensing Symposium (IGARSS'86) on Remote Sensing: Today's Solutions for Tomorrow's Information Needs, Zürich, Switzerland, 8-11 September 1986.

28. Jain, M.; Andersen, O.B.; Dall, J.; Stenseng, L. Sea surface height determination in the Arctic using Cryosat-2 SAR data from primary peak empirical retrackers. Adv. Space Res. 2015, 55, 40-50. [CrossRef]

29. Wingham, D.; Francis, C.; Baker, S.; Bouzinac, C.; Brockley, D.; Cullen, R.; de Chateau-Thierry, P.; Laxon, S.W.; Mallow, U.; Mavrocordatos, C.; et al. CryoSat: A mission to determine the fluctuations in Earth's land and marine ice fields. Adv. Space Res. 2006, 37, 841-871. [CrossRef]

30. Song, C.; Ye, Q.; Cheng, X. Shifts in water-level variation of Namco in the central Tibetan Plateau from ICESat and CryoSat-2 altimetry and station observations. Sci. Bull. 2015, 60, 1287-1297. [CrossRef]

31. Sørensen, L.S.; Simonsen, S.B.; Nielsen, K.; Lucas-Picher, P.; Spada, G.; Adalgeirsdottir, G.; Forsberg, R.; Hvidberg, C.S. Mass balance of the Greenland ice sheet (2003-2008) from ICESat data-The impact of interpolation, sampling and firn density. Cryosphere 2011, 5, 173-186. [CrossRef]

32. MSADC. Available online: http:/ / www.msadc.cn/en/sy (accessed on 5 September 2018).

33. Biancamaria, S.; Lettenmaier, D.P.; Pavelsky, T.M. The SWOT Mission and Its Capabilities for Land Hydrology. Surv. Geophys. 2016, 37, 307-337. [CrossRef]

(C) 2018 by the authors. Licensee MDPI, Basel, Switzerland. This article is an open access article distributed under the terms and conditions of the Creative Commons Attribution (CC BY) license (http://creativecommons.org/licenses/by/4.0/). 